\title{
Para una reforma evangélica de la Iglesia
}

\section{JOSE IGNACIO GONZALEZ FAUS, Facultad de Teología de Catalufa.}

\section{Introducción}

Las Páginas que siguen intentan desarrollar una tarea pendiente. Hace poco más de un año, y comentando el comienzo de la Lumen Gentium ("La Iglesia es... como un sacramento o señal... de la unidad de todo el género humano"), escribí que:

El Vaticano Il intuyó muy bien que el primer efecto de la salvación de Dios es la comunión entre los hombres, fruto y rellejo de la comunión con Dios... Esta necesidad de visibilizar la comunión impone a la Iglesia una serie de relormas estructurales que este artículo ya no tiene espacio para desarrollar y fundamentar. Me gustaría hacerlo en otro momento con algo más de calma y de argumentación. Aquí no cabe más que el enunciado de esas exigencias... Lo que sí me gustaría subrayar es que las propuestas que siguen brotan, en realidad, de la koinonia neotestamentaria y no meramente de la idea democrática moderna.'

Con el presente artículo llega ese "otro momento." La tarea consisle, por tan1o, en explicar y detallar un poco más esas reformas pendientes. No es ahora el momento de mostrar por qué la historia pasada de la Iglesia ha convertido en pendientes todas esas reformas: esto alargaría mucho el presente trabajo. Por tanto, nuestro recurso a la historia se haré sólo para mostrar la legitimidad de las propuestas que aquí se formulan: lo que en otros tiempos fuc legítimo puede serlo también hoy; y lo que en otros tiempos fue sólo una necesidad circunstancial, concreta, puede haber dejado de ser necesaria hoy. 
En los desarrollos que van a seguir, retomo, pues, y amplío, las mismas propuestas del citado artículo, modificando sólo la última de ellas, para alender a lo concreto y factible. En cierto modo, la reforma de una Iglesia que se autodefine como la semper reformanda, es una tarea imposible y siempre pendiente. Las reformas que aquí sugerimos no pretenden - ni de lejos-agotar todas las posibilidades de santificación de la Iglesia. Hay, desde luego, reformas más importantes que no pueden imponerse por decreto, sino que el Espíritu las va suscilando en el pueblo de Dios: así ocurrió antaño con las órdenes religiosas que nunca fueron fundadas ni concebidas "por Roma," sino que nacieron desde la base de la Iglesia; y así ocurre hoy también con algunas comunidades de base. Otras reformas son también más importantes que las aquí propuestas, pero son en exceso genéricas y, por eso, puede ocurrir que se acepten teóricamente y no acaben de cumplirse prácticamente (así ocurre, por ejemplo, con la opción por los pobres, en la cual nuestra Iglesia todavía se muestra en niveles cercanos a la tibieza).

Las reformas aquí sugeridas son, en este sentido, más sencillas, aunque puedan parecer radicales. Las elegimos por esta doble razón. En primer lugar, porque son concretas y resultan factibles ya desde hoy mismo. Al menos es factible el ir caminando hacia ellas y en la dirección que ellas señalan, la misma dirección marcada por el Vaticano II, el cual no fue en la Iglesia un paréntesis ni un episodio, sino un camino. La misma estruclura fuertemente autoritaria de la Iglesia las hace más posibles. Y por eso, en su formulación, parece que sólo afectan a la Iglesia de Roma.

En segundo lugar, porque son estructurales. Comparto la opinión de L. Boff, ${ }^{2}$ de que muchas de las conductas por las cuales la Iglesia resulta hoy escándalo, y nubla a Dios en lugar de transparentarlo, no dependen de la bondad o de la inlegri. dad de las personas, sino de la deficiencia de las estructuras. Las propuestas que siguen tienen, pues toda la necesidad y toda la insuficiencia de lo estructural. Tienen también toda su importencia: las estructuras son un elemento fundamental de la vi. sibilidad de la Iglesia y por eso afectan decisivamente a su carácter de signo o sacramento.

Finalmente -y esto huelga decirlo- no son relormas que se proponen desde la autoridad, sino desde el amor a la Iglesia y desde la legitimidad de la palabra libre en su seno. No aspiran, pues, a ser ejecutadas inmediatamente, sino a provocar y a preocupar. Provocar para que resulten discutidas, argumentadas, corregidas quizés. Preocupar para que se cree una comunidad de preocupación por el testimonio de la Iglesia ante el mundo moderno: porque ese testimonio - en una sociedad pluralista y en búsqueda como la nuestra - está llamado por Dios a convertirse en un motivo de credibilidad, y está aún lejos de haber conseguido eso.

\section{El Papa ;jefe de Estado?}

\section{Datos de la historia}

Es un dato conocido y obvio que, en los primeros siglos de la Iglesia, el papa no rigió ningún Estado. Sin embargo, a la caída del imperio iba poseyendo dominios cada vez máa grandes, como consecuencia de la progresiva estabilidad de la Iglesia y de la labor orientadora que realizaron los papas en aquellos siglos sacudidos por la inestabilidad y la desorientación. 
En el año 554, la Pragmática sanción de Justiniano concedió al papa algunos poderes de carácler político, como el nombramiento de funcionarios, el control de malversaciones, etc. Para el lejano emperador de oriente, estos lavores que él pretendía hacer eran más bien servicios que recibía, dadas las difíciles circunstancias del occidente post-romano. Esto no obstante (y siguiendo la tentación de todos los poderes), el emperador no dejó de intenlar cobrarse esos favores, imponiendo al papa determinadas servidumbres, como tributos, ratificaciones de la elección papal por los emperadores de oriente, etc.

Poco a poco, ante las presiones de funcionarios bizantinos y, sobre todo, ante la amenaza de los lombardos cuando se retiraron los bizantinos de Italia, el papado co. menzó a tener su ejército propio de delensa. A la vez, los papas Irataron de aprovechar las controversias dogmáticas de los orientales durante el siglo siguiente (monolelelismo, elc.), para ir obleniendo reivindicaciones ante el emperador.

Transcurrieron así unos siglos de constante tira y afloja entre papado e imperio. Un tira y afloja hecho de desconfianza, de necesidad mutua y de utilización. Hasta que el papado comenzó a mirar a Francia como modo de obtener la libertad. Y pronto llegó la ocasión histórica cuando esa mirada pudo concretarse en acción, y en acción política: a cambio del apoyo dado a Pipino el Breve, en el golpe de Estado contra los inútiles merovingios, los carolingios ayudaron al papa contra los lombardos, nombrándolo "jefe de Estado" para que pudiera defenderse. El papa "invistió," o consagró, al monarca carolingio, y recibió de él el poder político sobre los terrenos en torno a la diócesis de Roma (hasta Perugia, Ravena, etc.). Así nacieron a la vez el Sacro Romano Imperio y el papa jele de Estado. Esta operación coincidió sospechosamente con el "descubrimiento" de un documento ([alsificado) en el cual constaba la donación al papa, por Constantino, de todos aquellos territorios. Así aparecieron los "estados pontificios."

\section{Balance del pasado}

La historia de esos estados pontificios no necesita ser contada aquí. Baste con señaler que, también en ellos, se cumplió la dinámica corruptora de todo poder. El siglo siguiente fue el siglo "de hierro" del pontificado. La crónica de todos aquellos desmanes, -aunque se acepte sólo la tercera parte de lo que cuenta la Antapódosis del obispo Luitprando- parece increíble. La reforma gregoriana del siglo XI no fue definitiva. Y toda la edad media ha de soportar las lacras de simonía y corrupción moral de la curia romena, contra la cual casi en cada siglo se han elevado voces de santos y movimientos reformadores que, a veces, consiguen un triunfo momenténeo. La dinámica degeneradora continuó, sin embargo, hasta Trento; y, a veces, se mantuvo incluso en el seno de la corrección de abusos concretos. La reforma tridentina, como ya se ha dicho, llegó probablemente tarde. Y, a pesar de su radicalidad innegable, cabe preguntar si fue completa, es decir, podría afirmarse que Roma se reformó totalmente de lo que significaba Alejandro VI, pero quizá no de lo que significa. ban Julio II y León X: la inmoralidad personal desaparecio; pero quedaron la astucia política y el fasto mundano.

La cosecha tardía de todo eate "pecado original" apareció siglos más tarde; con el endurecimiento del papado y su incapacidad para entender el problema de la unidad italiana y de los estados pontificios. Historiadores como Döllinger quienes 
"veían venir las cosas," y trataron de preparar a los fieles explicando que los estados pontificios no eran exigidos por el Nuevo Testamento ni procedian de la voluntad de Jesucristo, fueron tachados de ser unos "judas." El libro del sacerdote Gioberti, ${ }^{3}$ uno de los primeros cantos a la unidad de Italia, fue puesto en el Indice por el cardenal Lambruschini. Entre tanto, el cardenal Antonelli, secretario de Estado, ordenaba "degollar todos los cabecillas rebeldes" apresados en un combate; el Syllabus de Pío IX condenaba la proposición de que "la derogación de la soberanía civil de al Santa Sede serviría mucho al bienestar y la libertad de la Iglesia;"4 y el papa reaccionaba con ira cuando (ya en 1861, y tras su primera derrota militar) se le propuso una solución de "Estado minúsculo" como la que luego había de abrirse camino. Es aleccionador observar que todas esas reivindicaciones acabaron imponiéndose, y que hoy esta problemática nos resulta a nosotros muy lejana y hasta ridícula: papas posteriores a Pío IX alabaron la solución actual como una bendición de Dios. Sin embargo, por no haberse resuelto a su tiempo, toda esta cuestión creó hipotecas difíciles a la Iglesia posterior: los católicos desaparecieron de la escena política... Y Pío XI hubo de "normalizar" la nueva situación del papa, pero tuvo que hacerlo dialogando... con Mussolini. Y esto le quitó liberlad para luego reaccionar con más vigor ante la invasión de Abisinia por el Duce: sólo encontró lamentos vagos, de extrema debilidad. Este es el peligro de no hacer las cosas a su tiempo.

\section{La situación actual}

Si de las lecciones del pasado intentamos aprender algo para el presente, hay que reconocer que la situación actual tiene claras ventajas con respecto a la de siglos anteriores. Lo ridículamente minúsculo del Estado Vaticano, evita toda sensación de que las intervenciones de Roma en la vida de las iglesias locales son "inje. rencias de una potencia extranjera," como tantas veces se decía, y como eslaba en la base de muchos sentimientos de tipo galicano, josefinista, elc. El Eslado Vaticano carece de aquellas "divisiones" por las cuales preguntaba Stalin, y es comprensible la satisfacción de los papas posteriores a Pío IX. En la situación actual se cumple lo que tantas veces ha ocurrido en la historia: que cuando se despoja a la Iglesia de riquezas mundanas, comienza prolestando, pero acaba por dar gracias a Dios. ${ }^{\mathbf{5}}$

Por otro lado, se ha dicho a veces que el hecho de conslituir un Estado "sobera. no," aun con su pequeñez, era una garantía de independencia para la Iglesia de Roma, llamada al servicio de la unidad entre todas las iglesias locales. Si el papado estuviese en el interior de cualquier otro Estado (y no digamos nada si se tratase de un Estado poderoso, como Estados Unidos o la República Federal de Alemania) éste trataría inevitablemente de manipularlo, y de poner a su servicio todo el enorme e inevitable poder mundial que representa una comunidad de 800 millones de seres humanos. La prueba de lo inevitable de esta tentación la suministran todos los intentos de presión que - ya en la siluación actual- ejercen sobre el Estado Vaticano los diversos "deparlamentos de Estado."

Ello nos lleva a considerar ahora los inconvenientes de la situación actual, tras haber enumerado sus ventajas. A pesar de lo minúsculo de su geogralía, el Vaticano, por el mero hecho de ser Estado, no deja de ser un acervo de poder mundano. Y esto puede contaminar la misión - no ciertamente política- del sucesor de Pedro. El só. lo hecho de ser jefe de Estado sitúa al papa (más allá de sus buenas intenciones) en 
un determinado "mundo," que no es el entorno en el cual Jesús estaba situado y recomendó situarse a los suyos. Los inlerlocutores naturales del papa pertenecen velis nolis al ámbito del poder terreno. Ello significa que la Iglesia de Roma está sometida a una ley de gravedad que la separa del mundo de los pobres y de los olvidados de la tierra, aunque no lo quiera, y más allá de su buena voluntad y de sus buenas palabras. Esos "pobres de la tierra" son el lugar natural de la Iglesia. En cambio, esa posición violenta de su centro coloca a la Iglesia en una atmósfera de protocolos, politiqueos, costos desmedidos, guardaespaldas, faustos y otras mil pinceladas de todo aquello que el lenguaje ascético tradicional llamaba "vanidades," y que Jesús recomendaba evitar, con el lenguaje de su tiempo (Lc. 10,4 ss.). No es teológicamente insignificante el que de tantos papas se haya contado la anécdota de que se sentían "prisioneros del Vaticano." Es algo que, hace ya muchos siglos, lo decía de sí mismo uno de los papas más interesantes que ha tenido la Iglesia, S. Gregorio I: "se puede dudar si el obispo de Roma hace el oficio de pastor o de príncipe temporal." "Esto sigue ocurriendo hoy - aunque el principado sea tan diminutopor la categoría que dan las relaciones internacionales a cualquier jefe de Éstado.

\section{De cara al futuro}

Si hay que buscar una solución que armonice las ventajas de la situación actual con la superación de sus inconvenientes, parece que ésta debería ir en la línea insinuada por alguna de las pasadas reformas administrativas de Juan Pablo II, pero radicalizándolas más y déndoles carácter institucional y permanente. El papa podría residir en el Estado Vaticano, pero no debería ser el jefe terreno de ese Estado, sino un ciudadano de él, como son ciudadanos los demás obispos en sus diversos estados. La jefatura del Estado Vaticano debería quedar reservada, bien a un laico, bien a un minislerio o diaconía constituida especialmente ad hoc. Ese jefe de Estado debería recibir la misión canónica de encarnar en su gobierno el carácter sacramental de la Iglesia como signo de la humanidad futura, reunificada y reconciliada con Dios. Y ello supondría sustancialmente estas dos cosas: ad intra, gobernar con el máximo de libertad y de justicia, y ad extra, garantizar la máxima independencia de ese Estado, y preservar para el ministerio del papa el máximo de libertad, en su relación armonizadora y unificadora con los pasıores de las demás iglesias.

No se presupone, ni mucho menos, que esta solución funcionará mecánicamen. le y sin roces desde el primer día. Nada en la tierra se ha conseguido así. Pero, aparte de la posibilidad de ir introduciéndola de manera gradual (como se hace, por ejemplo, en las reformas de la Comunidad Económica Europea), queda la necesidad humana de "hacer camino al andar" y de ir buscando solución a los diversos problemas, conforme aparecen. Pues esta es la condición humana y ser enviado de Dios no significa eludir esa condición.

\section{II. ¿Nuncios o embajadores?}

\section{Delensa de los nuncios}

Como muchos recordarán, en los días siguientes al Vaticano II hubo quienes hablaron y exigieron lisa y llanamente - y repetidamente- la abolición de los nuncios. Yo quisiera, al contrario, comenzar este capítulo con una moderada defensa 
del papel de los nuncios. Me parece mucho más conveniente que cada Iglesia local o conjunto de ellas, tenga su lazo de unión y su canal de comunicación con la Iglesia "centro" (y, al decir centro no quiero decir "poder central," sino factor de unidad y de comunión entre todas las iglesias particulares). Ese centro equilibrador (no suplantador) de las comunidades, que constituye el misterio petrino, parece impreacindible para evitar el poder inevilable de las iglesias rices sobre las iglesias pobres (o simplemente recientes), y el nefasto colonialismo larvado que ese poder comporta. ${ }^{7} 0$ para evitar la enorme inercia de encerramiento sobre sí mismas, que tiende a convertir en ghettos a las comunidades pequeñas, etc. etc.

\section{La situación actual}

Este lazo intercomunitario es, en mi opinión, necesario o muy conveniente; pero frustra su misión cuando se convierte en un cargo de embajador político. Y ello debido a estas razones. En primer lugar, el status y el entorno a donde se obliga a vivir al embajador. Este mundo ambienle impide necesariamente el conocimiento ex. periencial, el contacto y el "estar" con los pobres, quiénes son los verdederos "señores" de cada Iglesia local, según una formulación muy antigua, del diácono romano Lorenzo.

En segundo lugar, la investidura política convierte al "lazo de unión" en un "delegado del poder central," si no al nivel de la intención, sí a nivel de la imagen que se da, o de la figura que se encarna. De acuerdo con esa figura, el nuncio está más de parle de Roma ante los obispos, que de parte de los obiepos ante Roma. Viene siempre de fuera. Elige los candidatos a obispos. Si hace falta reprende a los diversos pastores. En este contexto (que, repito, es estructural, no personal) se vuelve comprensible la frase que escuché una vez a un obispo, "cuando los obispos hablamos por televisión no estamos pensando en el público sino en el Nuncio..." Y a la inversa, puede suceder que un nuncio determinado, por un buen servicio a una Iglesia local, se acarree conflictividades y llegue a poner en juego su carrera diplomática.

Por último, como se deduce de lo que acabamos de decir, las nunciaturas apostólicas, convertidas en embajadas diplomáticas, pasan a ser peldaños de un eacalafón, y esto da otros intereses a toda la acción del nuncio. En el mundo del escalafón diplomático es muy posible - y muy frecuente - que las embajadas que representan los peldaños más bajos de la carrera coincidan con les iglesias que viven horas máa difíciles y que, por consiguiente, necesitarían un nuncio de más experiencia y de más calidad (piénsese en lo que hoy ocurre en algunos países centroamericanos, por ejemplo). Y esto se vuelve prácticamente imposible por la coincidencia de la misión pastoral y del estatuto político.

De todas estas conaideraciones se sigue, además, con frecuencia, una información deficiente para la Iglesia de Roma, sobre todo respecto de las iglesias más enrevesadas o más conflictivas. Una información que no logra salvar esa distancia entre la vida "oficial" y la vida "real" que caracteriza a los poderes centralizados de este mundo. El mismo papa actual, (a pesar de que sus viajes están, montados por lo general, mucho más para "ser visto y oído" que para ver y escuchar), ha confesado en más de una ocasión, al regreso de algún viaje, cuánto crela haber aprendido en él. Y 
parece claro que, en ese "aprendizaje," el papa alude a algo más que a un paso de lo ya sabido a lo vivido.

\section{La reforma necesaria}

El sentido de la reforma buscada en este punto vendría dado por la misión ecle. siológica que hemos señalado para los nuncios: lazo de unión de las iglesias particulares con la Iglesia de Roma y - a través de ella - con todas las demás iglesias del mundo, en lugar de represententes del Estado Vaticano en los diversos estados. $\mathrm{Pa}$ ra ello, el primer paso debería ser separar ambes funciones. Si el diminuto Estado Vaticano ha de tener aus embajadores (o si éstos han de oer precisamente hombres del ministerio episcopal) es cosa discutible y que aquí no tratamos. Pero, en la medida en que ese embajador se distinga de la persona del nuncio, la figura de éste podrá configurarse mucho más de acuerdo con las necesidades pastorales de cada pais, y no de acuerdo con los estatutos de la diplomacia política. De hecho, a lo largo de la historia de la Iglesia han existido otras figuras de nuncio muy distintas del actual diplomático y, seguramente, más evangélicas. Fue sólo en el siglo XVI y a imitación de lo que hacian los estados laicos (con Venecia a la cabeza) cuando el papado comenz6 a abrir "embajadas" en diversos estados del mundo católico: en Gratz (1573), en Lucerna (1579), en Colonia (1580), en Bruselas (1606)... etc. Pero antes de esas embajadas habían existido ya otras formas de "nunciatura," poniendo así de relieve que la función eclesial del que hemos llamado lazo de las diversas iglesias locales con la Iglesia "unificadora," no coincide con el interés político de los diversos estados por tener representantes en otros países. Sustancialmente, el interés político es un interés egoísta, y la función eclesiástice debería ser una función hermanadora.

Entre eaas "otras formas" podemos citar la figura de quienes se llamaron lega. dos natos, que ni siquiera venían de Roma, sino que asignaban al obispo de alguna determinada diócesis (Toledo, Canterbury o Mainz, entre otras) la misión de delegado permanente del papa y ante el papa. Esta figura coexistió con otras como los "legados enviados" (quienes comenzaron a ejercer temporalmente misiones ante los soberanos), o los legados a latere, designados no de modo permanente, sino más bien para alguna misión particular o situación delicada. San Francisco Javier tuvo eae cargo de legado pontificio, y fue precisamente el carácter no político de su título lo que le permitió ejercerlo de manera "bastante singular en verdad," como escribe D. Rops, "desdeñaba las pompas y los faustos, arrodillábase humildemente delante del arzobiapo (el franciscano Juan de Albuquerque) y se alojaba en un hospital cuidando a los enfermos y aun a los leprosos."

Que ese papel de nuncio o de lazo no tenga que ser necesariamente realizado por un hombre de la curia, sino que, de común acuerdo, podría ser elegido a veces entre alguno de la Iglesia local (el secretario de una conferencia episcopal, por ejemplo), es una de las coses que deberían recuperarse del pasado. Con esta resituación de la ligura del nuncio se liberaría también la Iglesia de la costumbre adop. tada en el Congreso de Viena (1815) de que los nuncios vaticanos sean los decanos del cuerpo diplomático. Decisión que pudo ser útil en otra época, para evitar disputas de competencias y protocolos, pero que hoy, además de resultar más cercana al honor mundano que a la humildad evangélica, carece ya de sentido en un mundo tan pluralista y tan aecularizado, que ha roto ya el antiguo cordón umbilical con la cristiended. 


\section{Nombramiento de obispos}

Con el nombramiento de los obispos ocurre una cosa curiosa, cuando la Iglesia vivía en un mundo imperial -y totalitario por consiguiente-, elegía a sus obispos de manera democrática y se convertía así en un fermento y signo de comunión y de fraternidad ante la sociedad civil. Hoy, cuando la Iglesia vive en un mundo cuya conciencia hislórica ha aceptado ya los valores de democracia e igualdad, nombra a sus obispos de manera exclusivamente autoritaria, dando con ello al mundo el contratestimonio de un proceder "imperial" o de absoluta "planificación central," que produce escándalo. No se puede rehuir el imperativo de evitar este escándalo y este contratestimonio, apelando a que la Iglesia es un misterio. Pues también era un misterio la Iglesia cuando las cosas funcionaban inejor. Por eso debemos comenzar también este apartado recordando algunos datos ya conocidos.

\section{La práctice antigua}

Que en la Iglesia primitiva, las iglesias locales tenían ura participación mucho mayor, a veces casi total, en la designación de sus pastores, es dalo conocido, aunque esa forma de participación haya sido de hecho muy variada y diversa. Desde la elección de san Ambrosio por aclamación popular, cuando todavía no era más que un abogado de Milán, a la designación por los obispos de las iglesias cercanas, o "por acuerdo entre todos los miembros de la Iglesia" que es la fórmula que Rops define como más general ${ }^{9}$...las prácticas concretas han podido ser muy diferentes. Pero lo importanle, y lo que interesa subrayar aquí, es no sólo el prolagonismo de las iglesias locales, sino el que ese protagonisnı fuera alentado y exigido por la misma Iglesia de Roma. Muchos de los textos que se aducen al estudiar este tema son precisamente textos de papas: "que ningún obispo sea dado a una población contra su voluntad," es un precepto de Celestino I, el cual ha sido evocado más de una vez en los últimos años, ante determinado nombramiento. A su vez San León luchó lenazmente contra algunos metropolitanos quienes pretendían nombrar ellos solos a los obispos de su jurisdicción, sin contar con el pueblo ni el clero ni con los restantes obispos de la provincia: "no es lícito a ningún Metrojolitano consagrar obispo a alguien por su cuenta (suo arbitrio) sin contar con el consentimiento del pueblo y del clero, sino que debe poner al frente da la Iglesia al que haya elcgido toda la ciudad." 10

Estos y olros textos son importantes por cuanto toda la eclesiología antigua -y hoy citada en ocasiones de forma unilateral- condensada en la frase de Ignacio de Antioquía nihil sine episcopio, es una eclesiología que descansa a su vez en este otro axioma, nullus episcopus sine populo, el iual es tan sagrado como el anterior. De modo que invocar sólo uno de los dos poles sin el olro, es apoyarse en una verdad coja, en una de esas medias verdades que, a ver:es, son más engañosas que las mentiras.

Una prueba muy conocida de todo esto es el famoso episodio de la deposición de los obispos españoles de León, Astorga y Mérida (en el 254) por parte de su pueblo, bajo la acusación de debilidad durante la persecución de Decio. Los obispos depuestos apelaron a Roma que se inclinaba a darles la razón. Las iglesias de España acudieron a la autoridad de san Cipriano, que simpalizaba con ellas. Quiero no- 
tar que lo importante para nosolros en estos momentos no es quién tenía razón (per. sonalmente considero como muy probable que si estos obispos se escondieron no fue por debilidad o por apostasía, sino que pudiera obedecer a razones de "sana" política, y que Roma tuviera en este punto más Mexibilidad que el innegable rigorismo africano). Lo importante es el testimonio dado de un derecho de deposición de obispos por el pueblo, como consta por las siguientes palabras de san Cipriano en una carta a los fieles de aquellas iglesias:

El pueblo, obediente a los mandatos del Señor y temeroso de Dios, debe apartarse de un obispo pecador y no mezclarse en el sacrificio de un obispo sacrílelego, puesto que el pueblo tiene el poder de elegir a los obispos dignos o recusar a los indignos. Procede de la autoridad divina el que se elija al obispo en presencia del pueblo, a la vista de todos, para que todos lo aprueben comó digno e idóneo, por juicio de testimonios públicos... Dios manda que se elija al obispo ante toda la asamblea, y que no se verifiquen las ordenaciones sacerdotales sin el conocimiento del pueblo que asiste, de modo que, en presencia del pueblo, se descubran los delitos de los malos o se publiquen los méritos de los buenos, y así sea la elección justa y regular... Por lo cual, se ha de cumplir con diligencia, según la enseñanza divina y la práctica de los apóstoles, lo que se observa entre nosotros y en casi todas las provincias: que... alli donde ha de nombrarse un obispo para el pueblo, deben reunirse todos los obispos próximos de la provin. cia, y elegirse al obispo en presencia del pueblo, que congce perfectamente la vida de cada uno y conoció la acluación de su conducta.

De aquella situación antigua, que permite conocer estos y otros testimonios, se ha pasado - a pesar de las apelaciones a la autoridad divina y a la práctica de los apóstoles- a la situación actual que vamos a considerar brevemente.

\section{La situación actual}

Actualmente, sólo Roma interviene en la designación de los pastores de las iglesias locales, aun cuando trate de obtener una información que corre el riesgo de resultar deficiente, como dijimos que ocurre con todas las informaciones en los siste. mas muy centralizados. Pero el inconveniente más serio del procedimiento aclual no es sólo ese inevilable desgaste de las informaciones a través del roce. El inconveniente más serio es que el choque nalural de intereses que debería resolverse en un diálogo global, se decanta hacia una particularización unilateral. Por la naturaleza misma de las cosas (y al margen de la buena o mals voluntad de las personas) es inevitable que, a la hora de designar un pastor, Roma tenga unos intereses muy diversos a los de las iglesias locales: a éstas les interesan lógicamente lideres: hombres que sepan hacer caminar a través del desierto, como Moisés, y que puedan hacerlo precisamente porque cuentan con la confianza de los suyos. A la Iglesia central (que ya liene bastantes problemas en una inslitución tan enorme como la Iglesia calólica), le interesan lógicamente hombres fáciles, correas dóciles de transmisión, que eviten conflictos al centro. El líder local puede resultar difícil al centro (como se ha visto recientemente con Mons. Romero y con algunos obispos de la Iglesia brasi. leña). Mientras que el hombre fácil para el centro suele carecer de carisma ante los 
suyos, porque sólo es brazo del centro ante la periferia y no voz de la periferia ante el centro.

Las consecuencias que se derivan de esta situación son fáciles de predecir, y la práctica las confirma, el obispado se convierte demasiadas veces en un premio para una persona más que un servicio a una comunidad. La tentación del carrerismo amenaza al ministerio y lo desfigura. Y esto ocurre incluso aunque las personas particulares sean tan virtuosas que hayan logrado estar inmunes a esa tentación: porque el "premio" viene a ser la confirmación de que se ha ejercido bien el ministerio. Y esa confirmación no se apoyará en que el ministro haya sido fecundo para una co. munidad, sino en que no haya sido problemático para el centro. En Roma funcionan "listas negras:" un obispo auxiliar sabe que puede convertirse - como he oído de alguno- en "auxiliar crónico;" y un cura sabe muy bien que, a lo mejor, por una actuación evangélicamente exigida por las circunstancias, puede "jugarse el fuluro," porque ese futuro está todo en unas únicas manos. Es claro que, así, incidentes como el de Pablo en Antioquía ya no se repetirán nunca más; pero es claro también que audacias evangelizadoras como la de Pablo tampoco se repetirán nun. ca más, porque la obsequiosidad habrá prevalecido sobre la evangelización. Y, si no la obsequiosidad, por lo menos la burocracia o el espíritu administrativo. No dejaba de tener razón uno de los más famosos evangelizadores de Estados Unidos (Th. Combalol, 1797.1873) cuando, siendo testigo de la evolución del ministerio episcopal, en una Iglesia cada vez más centralizada, proponía con ironía y con amargura que se cambiase la fórmula de la consagración episcopal, y que en lugar de decir accipe baculum pastorale, se dijese accipe calamum administrativum ut possis scribere usque in sempiternum et ultra. 12 Esto es lo grave de la situación actual.

Todo cuanto estamos diciendo de manera genérica puede concretarse con anécdotas recientes: un nuncio comunica a un obispo que, por haber firmado un determinado documento público, se ha quedado sin una determinada archidiósesis a la cual se le pensaba trasladar. Durante uno de los últimos sínodos, un obispo latinoamericano comentó en Roma que, en un país de aquel subcontinente, al pedir informes para nombrar nuevos obispos, se había añadido la pregunta de si el candidato era "demasiado amigo" de los pobres. Las consecuencias de esta situación para las iglesias locales no son cierlamente esperanzadoras; y quizás la mejor prueba de ello sea un reciente y preocupado comentario del cardenal Tarancón, que es significativo sólo por el hecho de que se haya escrito, aún más que por lo que dice. ${ }^{13}$ Realmente, supondría muy poco amor a la Iglesia si alguien pensara que, ante una situación así, puede abdicar de la parcela de responsabilidad que tenga, y desentenderse de la marcha de estos problemas para limitarse a vivir en paz su vida privada de cristiano.

\section{De cara al futuro}

La reforma que la Escritura y la tradición parecen exigir a la Iglesia en este punto, tampoco consiste en la lotal independencia de las iglesias locales. En una "comunidad de comunidades," el factor "exterior" no sólo es importante, sino constitutivo para cada comunidad local. Y pienso que tenía razón Andrew Greele cuando, en el congreso de teólogos de la revista Concilium de 1970, comentó que si cada Iglesia local escogiera ella sola a sus paslores, muchas diócesis del sur de Esta. dos Unidos tendrían dentro de poco tiempo obispos literalmente racistas. 
Pero, sin abogar por la total independencia, sí que es necesario un influjo grande, efectivo y eficaz, de las iglesias locales en la elección de sus pastores. La elección debe ser fruto de un verdadero diálogo entre el centro y la periferia, de tal modo que los intereses de ambos polos queden salvaguardados (en incluso que el derecho de las comunidades a tener pastores verdaderos prime sobre el interés de Roma por tener peones fáciles de mover y poco conflictivos). Probablemente, la fórmula para eso tampoco existe todavía hoy, y hay que seguir buscándola a base de tanteos que luego se convertirán en normas. De haberse continuado con algunas experiencias aisladas y secretas, que comenzaron a hacerse poco después del concilio, quizás tendríamos ahora un material más probado con el cual esbozar unas primeras pautas de acción. Lo que es claro es que debe recuperarse la teología primitiva de la vinculación del obispo a la comunidad locah frente a la costumbre (que no teología) actual centralista por la cual el obispo se vincula en realidad a la curia romana y se le impone a la comunidad local. En este contexto también parece claro que deben desaparecer los obispos sin Iglesia (o in partibus) quienes también contradicen a la iglesia postapostólica, y son - como diría Ignacio de Antioquía- "como una cítara sin cuerdas," y uno de los factores que han ido contribuyendo a que el servicio a la comunidad se convirtiese en peldaño de un escalafón. La ficción jurídica de la designación in partibus, es hoy algo peor que una ficción, es simplemente una falsedad, la cual en modo alguno logra salvaguardar el principio de vinculación del obispo a la comunidad (aunque implícitamente lo reconoce y, en ese reconocimiento implícito, se desautoriza a sí misma).

$Y$, aunque todas estas sugerencias no son en absoluto nuevas, sino que están en la atmósfera eclesial desde hace ya bastante tiempo, me voy a permitir reforzarlas con la autoridad de unas palabras del cardenal Pellegrino, en los congresos de Milán de 1980 y 1981.

Otra causa de la situación de crisis a mi modo de ver... son los criterios que inspiran la elección de los obispos. Me da la impresión de que esa elección está hecha en gran parte por diplomáticos, porque proceden de la carrera diplomática y usan unos criterios diplomáticos que no se hasta qué punto se pueden lla. mar pastorales. Por ejemplo: buscar un puestecito para un nuncio fallido, confiarle a otro una diócesis, etc. $\mathbf{O}$ bien la elección es hecha por hombres de curia faltos de experiencia y de sensibilidad pastoral.

Son cosas que he dicho a quien debía decirlas hace ya tiempo, y de ahí que no tengo dificultad en repetirlas otra vez ahora aquí. El criterio que he visto que siguen con mucha alención en los últimos tiempos es la cautela con respecto a los "izquierdosos." Si se escapa alguno hay que poner en torno a él un cordón sanitario.

$\mathrm{Y}$ sucede lo que sucede. $\mathrm{Y}$ luego -y eslo es muy grave- algunos obispos recientísimamente han sido elegidos sin consultar ni a la con[erencia episcopa] regional ni a su presidente. Y esto es grave. ${ }^{14}$

\section{Elección del sucesor de Pedro}

También, a lo largo de la historia, el papa ha sido elegido de muchas maneras. Y es claro que aquí la Iglesia ha tenido que luchar por salvaguardar su liberación 
del acoso de los poderes políticos. Todavía están reciente los tiempos cuando el cardenal Rempolla no pudo acceder al papado, por el veto de Austria. Y hay que agradecer a Pío X (que fue quien hubo de sustituirlo) el que aprendiera la lección y tuviese valor para acabar definitivamente con la práctica del veto de los estados, que hacía tiempo que debería haber sido abolida.

En el extremo opuesto (y esta vez no a comienzos del presente siglo, sino a comienzos de este milenio), en 1073 el monje Hildebrando fue aclamado papa a gritos por el pueblo, mientras asistía a los funerales del que había sido su antecesor: "[Hildebrando es el que san Pedro elige por su sucesor!" comenzó a gritar la multitud. Hildebrando entonces no era ni siquiera presbítero. Pero los cardenales escucharon la voz del pueblo, se reunieron en san Pedro ad vincula, y preguntaron oficialmente al pueblo: Placet vobis? Vultis eum? (¿les gusta? ¿lo quieren?).5 Un mes más tarde Hildebrando recibió el presbiterado y 2 meses después el episcopado. Esta elección de Hildebrando, como ya es sabido, hizo posible la reforma de la Iglesia en horas dificilísimas (infinitamente más difíciles y más degradadas que las actuales), aunque tuvo sus costos importantes en la progresiva y excesiva centralización de la Iglegie, la cual ha perdurado durante todo el segundo milenio, y contribuyó decisivamente a la incomprensión y separación del oriente.

Hoy, la elección del obispo de Roma por los cardenales resulta ya tan obsoleta como antaño su designación por las familias de los Orsini o los Colonna. La intuición de Pablo VI, quien luego no consiguió (o no lo dejaron) llevar a cabo, señalaba mucho mejor los caminos que el evangelio parece dictar a la Iglesia, al menos para un futuro inmediato: el conclave debería estar compuesto por los presidentes electos de las distintas conferencias episcopales. En mi opinión, y para introducir una dosis mayor de representatividad y de comunión en aquella Iglesia cuya misión es "presidir en el amor," 16 habría que añadir a ese conclave otros elementos repre. sentativos del laicado (aunque ajenos a los poderes políticos), de las órdenes religiosas (vg. algunos generales de congregaciones masculinas y femeninas) y algún representante del presbiterio de la Iglesia de Roma.

Es posible, sin embargo, que toda esta reforma, que asustará a unos, todavía parezca a otros demasiado tímida y - lo que es más serio- teológicamente discu. tible, por la escasa representación del presbiterio romano, cuando el papa es, antes que nada, el obispo de Roma. Pero, aun aceptando el posible peso de estas obje. ciones, creo que la reforme que hemos sugerido sería, no obstante, un paso importante. En este trabajo nos queremos limitar a aquello que parece ya hoy posible y factible. No olvidamos por ello que el Espíritu de Dios ya se encarga de ir conduciendo a los hombres por caminos sucesivos (y tantas veces imprevistos), cuando los hombres han sabido ser dóciles en los primeros pasos.

\section{Una Iglesia sin príncipes}

\section{Ojeada histórica}

El cambio en el sistema de elección del obispo de Roma llevaría aneja la desaparición de los cardenales. Quizás convenga comenzar recordando que los cardena. les no son institución de Jesús ni de los apóstoles. Si, tal como se ha hablado hoy, las 
conferencias episcopales tienen poco fundamento teológico el cardenalato está tristemente huérfano de fundamentos teológicos, aunque tuvo una razón de ser histó. ricamente válida. Los cardenales eran antaño algo así como el consejo presbiteral de la diócesis de Roma ( presbyteri cardinales, de "cardo," quicio). En 1059, en un sínodo de Letrán, el papa Nicolás II, para escapar a las presiones y dictados del poder imperial en la designación de los papas, confió a ese consejo de la diócesis de Roma la elección del papa. Era un acto de fidelidad apasionada a la libertad de la Iglesia, y de una audacia revolucionaria como muy pocos papas tendrían hoy. La prueba está en las reacciones que produjo y en lo que costó implantarlo, porque rompía con la evidencia de lo establecido que suele ser la peor de todas las evidencias... El decreto de Nicolás II fue seguramente falsificado, puesto que se conservan de él dos versiones: una que pasó al Decretum Gratiani y que debe ser tenida como auténtica, y otra mucho más favorable al emperador germánico. Según la primera versión, los cardenales harían la elección, la cual luego debía ser aprobada por el clero restante y el pueblo romano; y todo esto salvo debito honore et reverentia dilecti filii nostri Henrici frase suficientemente ambigua para no implicar demasiado al emperador Enrique IV. En cambio, según la segunda versión, parece que el emperador intervendría junto con los cardenales en el momento mismo de la elección. ${ }^{17}$

Pero no fueron éstas todas las resistencias. Ya a la muerte de Nicolás II, cuando se puso en marcha el decreto y se eligió a Alejandro II, toda una fracción de la corte romana, opuesta al decreto del papa Nicolás se alió con el emperador para elegir otro papa: el obispo de Parma Honorio II. Esa fue una de la varias situaciones de cisma por las que la Iglesia ha pasado, la cual originó tensiones violentas y hasta luchas sangrientas; y no se arregló hasta la muerte de Honorio II.

En cualquier caso, esta es la primera aparición del "colegio cardenalicio" en la historia de la Iglesia. Más tarde, la evolución centralista de la cual ya hemos habla. do como característica del segundo milenio, se fue rellejando también en la estructura del colegio cardenalicio, que, poco a poco, fue pasando de ser el "consejo presbiteral" del obispo de Roma, a aer esa especie de corte particular, que el papa se nombra de entre toda la Iglesia universal, para que designe a su sucesor. En 1586, con la bula Postquam verus ille, Sixto V dio al Sacro Colegio las bases en las cuales, sustancialmente, se mantiene hasta hoy. Sólo que entonces el número de cardenales se fijó en 70 .

\section{Tarea evangélica}

Los cardenales fueron, pues un recurso audaz y legítimo para rescatar la libertad de la Iglesia en la designación del papa respecto del poder civil. Hoy que esa libertad ya se ha conseguido (sobre todo tras haber abolido Pio $\mathrm{X}$ el derecho de veto de los estados) no parecerá exagerado decir que el colegio cardenalicio ya no tiene demasiada razón de ser. Y el mantenimiento de algo que no tiene razón de ser es lo que puede contribuir a que se deslicen falsas razones que lo convierten en lo que san Ignacio llamaba un "vano honor del mundo." Se ha hablado así de los cardenales como "príncipes de la Iglesia," expresión por demás desafortunada, que escandajiza a la sensibilidad moral de hoy y que olvida no sólo que en la lglesia del carpintero no hay príncipes, sino sobre todo que - en todo caso- los únicos príncipes 
de la Iglesia son los pobres. Así se convierte también el cardenalato en un hipotético "premio" para las aspiraciones de los obispos que, con ese señuelo, podrían volver. se más manejables para Roma (y no decimos que esto ocurra de hecho, pero sí que es una tentación o peligro estructural el cual debería evitarse, por cuanto no tiene contrapartida razonable que lo justifique). 0 también, el cadenalato se convierte en un privilegio honorífico para ciertas díócesis (¿por qué, por ejemplo, París o Toledo han de ser diócesis cardenalicias?) que, si luego no es respetado (a lo mejor por comprensibles razones funcionales, más que personales), genera descontentos, sospechas o cábalas, que no contribuyen a la limpieza en la Iglesia y que también serían fácilmente evitables.

Por todo esto, no me parece exagerado decir que la desaparición del colegio cardenalicio volvería hoy a la Iglesia más evangélica y más sacramento de comunión entre los hombres, sin implicar ningún costo práctico importante, más que el costo de la costumbre. Y que su permenencia hoy podría ser más bien uno de esos casos en los cuales la sociedad religiosa desoye la voz de Dios por acogerse a las tradi. ciones de los hombres (Mc. 7,8).

\section{Curia romana y colegialidad}

La colegialidad episcopal, proclamada oficialmente por el Vaticano II, está aún por estrenar en la vida de la Iglesia. Cuestiones que son de responsabilidad de todo el colegio episcopal con su cabeza, se ven con demasiada frecuencia hurtadas a esa responsabilidad, y terminan en la decisión de algún subsecretario de alguna congregación imprecisa. Y esto no siempre por comprensibles urgencies prácticas de funcionamiento, sino a veces por razones de principio, lo cual es mucho más grave.

La colegialidad es voluntad del Señor. Es, de todas las estructuras de la Iglesia, la que más fácilmente encontraría un fundamento en la praxis del mismo Jesús y en la Iglesia del Nuevo Testamento o en los textos fundacionales de la Iglesia. Es cierto que el papa sólo puede ser también cabeza de la Iglesia universal; pero hay que añadir que, si esto lo hace sin razones, por puro afán de poder o de centralismo, ello constituiría una falta de respeto al derecho moral de los obispos, aunque fuera jurídicamente correcto: sería abusivo y hasta inmoral. El pepado en nuestros días debería tener como su primer mandamiento aquellas famosas palabras del papa Gregorio Magno al patriarca de Alejandría, tanlas veces citadas y lan pocas atendides:

Habéis grabado un título soberbio en la carta que me escribisteis al llamarme 'papa universal.' Ruego pues... que no lo volváis a hacer, pues se os quita a vo. solros lo que se da a otro por encima de lo que pide la razón. Y yo no quiero prosperar en títulos sino en costumbres. No tengo por honor aquello en lo que veo que mis hermanos pierden su honor. Pues mi honor es el honor de la Iglesia universal. Mi honor es el sólido vigor de mis hermanos. Y me siento verdaderamente honrado cuando no se niega a nadie el honor que se le debe. Pero ai vuestra sentidad me llama 'papa universal,' niega ser lo mismo que me reconoce a mí: universal. Ni hablar de eslo. Lejos todas las palabras que hinchan la va. nidad y vulneran la caridad. ${ }^{18}$ 
Es importante recuperar estas palabras porque, con la colegialidad, se juega la Iglesia (además del tener unas estructuras de verdadera koinonía), el poder ser de veras católica, universal. El principio tantas veces proclamado, de que no hace falta dejar de ser africano ni dejar de ser filipino para ser católico, se ve hoy deamentido por demasiadas prácticas; y la razón es que el ser "católico" está unilateralmente apropiado y polarizado por el ser "romeno." Las excelentes palabras de la reciente instrucción vaticana sobre "libertad y liberación" en las cuales se habla del principio de subsidiariedad en las sociedades, ${ }^{19}$ parecen no tener vigencia precisamente para aquella sociedad que gusta definirse como sociedad "perfecta." Con la actual centralización, Roma ha dejado de ser el factor de unidad y de comunión de lo "católico," para convertirse en su propietaria privada. Y una Iglesia que no sea de veras "católica," niega una de sus notas esenciales y se incapacita para ser misionera. La mera internacionalización de la curia, que antaño pudo ser un paso adelante, se revela hoy muy insuficiente, porque el problema de la universalidad no es un problema meramente de origen (como si, por ejemplo, los franceses fueran más listos que los italianos y todo se arreglase con hacer monseñores franceses en lugar de hacerlos romanos), sino que se trata de un problema de situación y de ubicación.

Y si todo esto es así, parece lógica una cosa que ya se reclamó repetidas veces durante el Vaticano II: el órgano gestor del gobierno de la Iglesia debe ser un órgano al servicio de una cabeza de la Iglesia que está formada por el colegio episcopal junto con el papa. Esto debería ser al menos el presupuesto normal y el fondo último de la gestión eclesial, sin perjuicio de que luego, razones de urgencia o de sentido práctico, aconsejaran en ocasiones procedimientos más ligeros. Se evitaría con ello un cierto trato prepotente de la curia romana con respecto a muchos obispos, así como la falta de libertad de algunos de ellos por miedo a dañar su carrera ante Roma. Ese trato se ampara muchas veces vagamente en la autoridad del papa (quien, en ocasiones, ni siquiera tenía noticia de él...) y es una de las cosas que más ha contribuido a dañar la imagen del papado, tanto teológica como ecuménicamente.

También aquí se han de inventar las formas concrelas para que la curia eaté al servicio de todo el colegio episcopal. Es la fe en su Señor la que obliga a la Iglesia a probar e imaginar, en lugar de poner su seguridad en rutinas quizás más cómodas, pero a lo mejor más estériles también. No es absurdo pensar que la lacilidad de comunicaciones del mundo moderno permitiera a la Iglesia una mayor diseminación local de sus organismos administrativos, de acuerdo con los diversos campos de acción concretos con los cuales esos organismos tienen que ver. En este mismo sentido de Cormas a inventar, puede ser bueno recoger aquí la propuesla que hizo durante el pasado sínodo extraordinario de 1985, el arzobispo ucraniano Máximo Hermaniuk, quien pidió la constitución de un sínodo permanente de obispos, que asuma el poder legisla livo que hoy el papa comparte sólo con la curia, dejando para ésta una función meramente ejecutiva. Semejante propuesta va en la línea de lo que decimos en este apartado y, a la vez, toca también lo que vamos a decir en el siguiente.

\section{Un sínodo de obispo deliberativo}

Otra expresión de la colegialidad episcopal lo sería el hecho de que el sínodo ordinario de obispos, el cual se celebra cada 3 años, tuviese un carácter deliberativo 
y no meramente consultivo. De este modo, el sínodo vendría a ser como una representación permanente del concilio ecuménico, con su cabeza el papa.

La propuesta no implica que necesariamente, en todas sus reuniones, el sínodo haya de llegar a alguna decisión. A veces, la complejidad o inmadurez del tema tratado, y la escasez de tiempo, lo impedirán. $Y$, aun en estos casos, el mero intercambio de experiencias y de opiniones entre los obispos no carece en absoluto de valor. Pero sí implica que, en aquellos casos en los cuales se llegara a alguna decisión o documento final, éste tendría carácter vinculante para toda la Iglesia.

Aparte de las razones teológicas sobre la colegialidad, aludidas ya en el apartado anterior, existe una razón práctica o pastoral para esta propuesta. Y se la puede expresar con el relrán castellano: la unión hace la fuerze. Tanto el Vaticano II como algunos sínodos posteriores han mostrado con machacona insistencia que los obispos son mucho más audaces cuando se encuentran juntos que cuando están solos. Las repetidas anécdotas de libertad de los obispos, y su resistencia a dejarse manipular o a aceptar pasivamente los documentos y planes preparados por la curia, no son exclusivas de este siglo. Se dieron incluso en el Vaticano l. A su vez, los obispos así unidos resultarían un apoyo enorme para el centro eclesial, en lugar de dar la sensación actual de que necesitan afirmarse frente a él. Por paradójico que pueda parecer, es un dato de experiencia que en los últimos tiempos el papado nunca ha ajdo más apreciado que durante el Vaticano II. Y es que el destino de todos los pode. res demasiado centralizados es la soledad. La soledad genera une sensación abrumadora de responsabilidad la cual, a su vez, produce miedo. Pablo VI confesó una vez que él solo no se hubiese atrevido a firmar la reforma litúrgica, de no haberle constado que la deseaba todo el episcopado católico y que ahí podía ver una clara señal del Espíritu. De esa soleded del poder centralista no es posible escapar ni mediante la adulación más o menos programada, ni mediante la secreta prohibición de toda crítica, ni mediante eso que recientemente, y en altas esferas, se he vuelto a llamar "papolatría." Todos esos son los caminos del espíritu del mundo el cual, queriendo salvar su vida, la pierde (Mc. 8,33). De la soledad de una responsabilidad excesiva se escapa mediante el camino normal otorgado por el creador a la naturaleza misma de las cosas: la comunión que - en este caso- se convierte en responsabilided compartida, en corresponsabilidad.

El sínodo deliberativo podría ser hoy una de las expresiones más adecuadas de esta corresponsabilidad.

\section{Finanzas vaticanas}

\section{Examen de conciencia}

Pasados escándalos y estados de opinión extendidos hacen que el tema de las finanzas vaticanas sea de aparición obligada en cualquier esbozo de reforma de la Iglesia. Las reuniones de cardenales, prácticamente secretas, convocadas por Juan Pablo II, parecen confirmar esta opinión. Y la influencia del peso de este problema en la muerte repentina del papa Luciani (aun prescindiendo o negando por completo todas las hipótesis fantasiosas sobre un presunto envenenamiento) ae ha abierto también camino como una sospecha digna de ser atendida, la cual contradice las convencionales versiones oficiales. 
Aun cuando la elaboración de proyectos de reforma en este punto sea de competencia exclusiva de los técnicos, el té́logo sí que puede insinuar los objetivos a los cuales esa reforma debe apuntar, o los valores a los cuales debe servir, dado que ninguna ciencia es neutral, y la economía menos que ninguna. $Y$ dado sobre todo que los valores a los cuales tácitamente sirve la economía en nuestro mundo (valores de máximo rendimiento y de máximo beneficio personal), aparecen como contrarios a los valores evangélicos, tan pronto como ae los explicita mínimamente. Las pasadas declaracionea del arzobispo Marcinkus ("yo no sé si la Iglesia ha de tener un banco o no; pero si lo ha de tener, entonces hay que dejarse de ingenuidades y ser realmente banquero'") cometen un reduccionismo muy serio, que subordina el patrimonio de la Iglesia a la pura lógica de la economía occidental Más bien habría que argumentar en sentido inverso y decir que, si para tener bienes, la Iglesia necesitara comportarae como los banqueros de este mundo, eso sería una señal clara de que no debe tenerlos: de este modo se dilucidaría la condicional que Marcinkus dejaba cómodamente en el aire.

Tampoco escaparía la Iglesia de la radicalidad del evangelio en este punto, limitándose a poner sus bienes en manos ajenas, y contentándose con exigir sólo rentabilidad; pero desentendiéndose de cómo ha sido conseguida esa rentabilidad. Semejante manera de decir "tómenlo allá ustedes y... yo me lavo las manos," no liberaría a la Iglesia de la culpa de Pilatos. Una cooperación material que no aeja de existir porque se pretenda ignorarla. Por otro lado, dedo que el dinero es hoy -en nuestro mundo occidental - la mayor y más verdadera fuente de poder, habría que anadir que un arzobispo-banquero tiene todavia menos sentido que un cura diputa. do o ministro. Y que, precisamente en el caso de la Iglesia de Roma, llamada a ser ejemplo y a "presidir en el amor," no puede aceptarse la hipótesis de una situación límite o excepcional, que permiliera dejar interinamente en suspenso los principios.

Por la confluencia de todos estos indicios es por lo que en otra ocasión escribí, a modo de ejemplo, las líneas que deberían ir marcando esta reforma:

Que las finanzas desaparezcan tanto de manos sacerdotales, como de unas manos laicas que actúan como meros administradores ajenos a la Iglesia, y sin otra lógica que la lógica de la economía. Debería crearse para ellas una especie de consejo ad hoc un nuevo 'cuerpo de diáconos' (cf. Hch. 6,1-6) que arrastrase además la aventura extraña (y mundanamente insensata) de un máximo de publicidad para su gestión. ${ }^{20}$

\section{Aprender del pasado}

El ejemplo de lo que ae lamó antaño el Patrimonium Petri puede servir como fuente teológica de inspiración, para buscar en este punto unas estructuras y unas prácticas eclesiásticas que se sintieran más atentas a salvaguardar plenamente la ortodoxia evangélica que a salvaguardar la ortodoxia económica.

No es este el momento de discutir si fue plenamente legítimo y evangélico el proceso que convirtió a los papas en grandes terratenientes. En una época de expolios de absoluta inseguridad, de abandono de la agricultura y de toda forma de administración ante las amenazas constantes, puede ser comprensible el proceso que fue convirtiendo la propiedad del sepulcro de Pedro en la vía Cornelia, o del cementerio de Calixto y las basílicas de Pedro y Pablo, en un enorme patrimonio. Eran 
muchos los patricios romanos que entregaban sus bienes al sucesor de Pedro: unos al morir, otros - como el futuro Gregorio I- en la plenitud de su vida, a raíz de su dedicación a Dios, y para reencontrarlos más tarde como papa. Sabemos que ya desde el siglo V -con san Gelasio- existían catastros y libros de censo de las tierras y rentas del papado.

Pero, aun sin discutir esta peligrosa evolución, si cabe reflexionar algo sobre la administración de ese patrimonio. Señalaremos dos principios teológicos importantes de la práctica antigua. En primer lugar, los pepas consideran su propiedad como una dispensatio in rebus pauperum, son administradores de bienes que pertenecen a los pobres. Y esta será una de las razones más serias que esgrimirán los grandes críticos de siglos posteriores (como san Bernardo o santa Catalina de Siena) contra el abuso de esos bienes por parte de los papas. " $\mathrm{Mi}$ intento -escribía san Gregorio I- no es hacer negocio con ganancias torpes,sino aliviar a los pobres." $Y$ es innegable que la gran popularidad de los papas, en los duros siglos V, VI, VII y VIII, vino de aquí. Por eso es también lamentable que ese principio haya desaparecido del actual derecho canónico de la Iglesia.

Además de esa "propiedad de los pobres," está el dato de que los administra. dores del Patrimonium Petri (que eran diáconos, subdiáconos o notarios eclesiásticos), se vinculaban todos con un juramento por el cual - aparte de otras promesas referentes a su conducta personal- se comprometían a cosas como "percibir las rentas sin daño de los colonos," "no marcharse con el lucro" y "repartir limosnas entre los pobres." 23

Ambes cosas no pueden sin más reproducirse hoy. Las iglesias con las que hoy se relaciona la Iglesia de Roma viven situaciones, algunas muy diferentes y otras a lo mejor bastante similares a las que vivían las iglesias europeas anteriores al año 1000. En los países del llamado primer mundo la diferencia es de 180 grados con respecto a entonces. No se trata, pues de querer reproducir al pie de la letra nada de lo dicho. Pero, sin embargo, tomadas como principios teológicos más que como normas canónicas, las prácticas antiguas deberían seguir siendo fuente de inspiración para nuestros días. Pues no se puede decir que la actual praxis económica del Vaticano se apoye en aquellos mismos principios tan evangélicos. El teólogo puede pronunciar un juicio de este tipo, aunque no debe pretender decir más. actual.

Pero un juicio de ese tipo es precisamente lo grave de este tema en su situación

\section{Mejorar las relaciones entre la congregación de la fe y los teólogos}

Debo comenzar este punto reconociendo que, como profesional de la teología soy, inevitablemente, parte interesada, y mi reivindicación se vuelve por eso mismo sospechosa. Por ello quiero proclamar de entrada que este punto es para mi muy secundario y el menos importante de este decálogo: quizás sólo figura aquí por un cierto prurito "estético" o literario de respeter el esquema decimado. Pero los té́ logos no deberíamos olvidar nunca que sólo somos servidores de la comunidad eclesial, y que tiene profunda razón aquel ejemplar comentario de G. Gutiérrez en horas recientes, "lo importante no es mi propio dolor sino el dolor de mi pueblo." 
Los téblogos deberíamos dar por bien empleadas todas nuestras tribulaciones, ai ellas sirvieran para ayudar a la causa de los pobres.

\section{Factores del problema}

El problema comienza cuando, a veces, las tribulaciones de algunos teólogos no parecen fructificar para esa causa, y uno tiene que contemplar a personas ejemplares maltratadas (y maltratadas de manera quiź́s abusiva y, en ocasiones al menos, innecesaria).

El problema se agranda, además, porque éste es uno de los puntos en los cuales, tanto la mentalidad cultural como la sensibilidad ética del mundo moderno, son más exigentes para con la Iglesia: toda plausible asimilación de la ortodoxia creyente a una ortodoxia de partido, semejante a la de los países del este, daña a la fe infinitamente más que una formulación imprecisa o hasta insuficiente. $Y$ aunque es innegable que muchas cosas han cambiado, quiź́s han cambiado tarde, y Roma no parece tener la necesaria sensibilidad para con esa mentalidad moderna que, en el Condo, es correcta.

Y aún hay más. El problema sigue agrandándose porque esa mentalidad ética moderna incide además sobre otro dato cultural que también es incuestionable, al menos como experiencia del occidente, la enorme relatividad de todo lenguaje, aun en medio de la absolutez de la verdad que el lenguaje pretende vehicular. Tampoco se puede decir que Roma haya asimilado ouficientemente este dato cultural, a pesar de que las lecciones de la historia son en este sentido bien claras: jcuántos herejes condenados han podido más tarde ser leídos de otra manera o incluso parcialmente rehabilitados! „Cúntos santos o teólogos han sido malentendidos, deformados e innecesariamente perseguidos! Por aquello de que desde más distancia se ven las cosas con perspectiva más global, trataré de evocar ejemplos ya lejanos y que hoy no molestan a nadie: la inquisición española retiró obras como el Audi Filia de san Juan de Avila, la Guía de Pecadores y el tratado De la oración y meditación de Fray Luis de Granada, la Obra del cristiano de san Francisco de Borja, etc. etc. Un hombre tan poco sospechoso como san Pedro Canisio calificaba de "piedra de escándalo" el Indice de libros prohibidos confeccionado por Paulo IV. La comisión bíblica prohibió enseñar, a comienzos de este siglo, la mayoría de las opiniones exegéticas que se enseñan hoy...

Pero no se trata de hacer aquí un catálogo de bazas o una lista de reclamaciones. Sé muy bien que igualmente podría hacerse otra lista aun mayor, con insensateces (tantas veces vanidoses) de té́logos. Que exista un problema es normal; viene dado por la misma naturaleza de las cosas. Lo importante es ir aprendiendo a plantearlo y a resolverlo. Y para ello me limitaré a citar dos textos - uno antiguo y otro reciente- que considero deberían ser programáticos para la congregación de la le.

\section{Lecciones de la historia}

En primer lugar unas palabras de Gil de Roma, discípulo de Tomás de Aquino, escritas en defensa del maestro en sus horas duras, y oportunamente recogidas por Evangelista Vilanova, de quien las tomo: 
Ha habido gente que se ha complacido en denunciar como errores las opiniones de sus colegas teólogos que formulan nuestra fe e iluminan la Iglesia. Es una precipitación que implica un gran peligro para la fe. El trabajo de los teólogos, gracies a los cuales avanzen en las vías de la verdad, demanda efectivamente una corrección benevolente y libre, no por un detractor anatematizador. Que callen los censores. Son muy libres de tener una opinión contraria; pero que no acusen a otro de error porque ello es a la vez un juicio precipitado y una debilidad de espiritu. 24

En segundo lugar, unas palabras de Mons. Bekkers, obispo entonces de Bois-leDuc, y que proceden de los años inmediatos al Vaticano II, y marcan el nuevo espiritu que por aquel tiempo ee buscaba para la Iglesia en este punto, y que no se ha acabado de conseguir.

Si uno no se considera capaz de seguir a un teólogo en sus reflexiones, no tiene por qué reprochárselo ni ha de sentirse por ello un retrasado mental. Nadie está obligado a seguir a los teólogos en sus especulaciones. Pero, si se atreve a formular un juicio sobre las ideas de un teólogo, entonces sí debe - sin ningún género de duda - asegurarse que le ha entendido perfectamente, e interrogarse acerca de sí, juzgándolo, no incurrirá en la maledicencia o - lo que es peoren la calumnia:25

Permítaseme afirmar sencillamente que, con los teólogos, se incurre a veces en la maledicencia o en la calumnia, y que no son éstas las mejores armas para defender la verdad cristiana. Tampoco creo que la verdadera causa de estos pecados esté inmediatamente en la congregación de la fe, sino más bien en esos otros personajes a los que aludía Gil de Roma al comienzo de su cita: los denunciantes. En la Iglesia funcione demasiado la denuncia. Muchas veces anónima. Y tiene demasiada audiencia, aunque quizás en Roma pensarán - vistas las cifras - que le dan demasiado poca. El tenebroso clima de La Sapinière de Mons. Benigni parece que está renaciendo en los últimos años, a peasr de la doliente petición del obispo de Estras. burgo Mons. Weber: "que nunca más vuelvan aquellos tiempos." 26

La denuncia es une práctica oscura que viene arrastrando la Iglesia desde los tiempos de la inquisición, en los cuales sirvió muchas veces (como sirve también en las sociedades civiles) para venganzas personales mezquinas y no para defender la verdad de Dios. Y por todo lo que ya hemos repetido varias veces en este trabajo, acerca de la angustia de falta de información, típica de los sistemas muy centralizados, hay que añadir ahora que Roma sólo se librará de ser víctima de estos pobres hombres, si pone radicalmente en juego el principio que ella misma acuño, y que hoy ha pasado a ser norma de todas las sociedades civilizadas: el de la presunción de inocencia de todo acusado, que san Ignacio de Loyola formuló con aquellas célebres palabras, fruto también de su amarga experiencia en este punto:

todo buen christiano ha de ser más prompto a salvar la proposición del próximo que a condenarla; y ai no la puede salvar, inquiera cómo la entiende, y si mal la entiende corrijale con amor; y si no basta, busque todos los medios convenientes para que, bien entendiéndola, se salve. ${ }^{27}$ 
Porque no es preciso recurrir a complicados psicoanálisis para percibir que, en el inconsciente del denunciante, no trabaja el deseo del triunfo del evangelio, sino el deseo de defensa propia y del triunfo propio (aun cuando él quizás se engañe sobre eso), y que la denuncia no sirve tanto para proteger la verdad, cuanto para dar salida a frustraciones personales, sobre todo cuando es anónima. ${ }^{28}$ También aquí es iluminador, aunque doloroso, volver los ojos al pasado y trater de aprender de la historia. Para no citar más que un ejemplo, permitaseme evocar algunas de las acusaciones contra san Juan de Avila ante la inquisición española: que había dicho en el confesionario que los quemados por la inquisición eran mártires; que decía que el cielo es para los pobres y labriegos y que es imposible que los ricos se salven; que no había por qué maravillarse de las comunicaciones de Dios a mujeres, puesto que viene diariamente a manos de los sacerdotes... 29 Léanoe también las respuestas de Juan de Avila para percibir cómo desfigura el acusador. ${ }^{30} \mathrm{Y}$ figuras como les de ese acusador son inevitables en toda gran comunidad.

Por otro lado, la pura actuación negativa tampoco defiende la verdad, más bien acaba dando armas inútiles a le postura que pretende combatir. Así ha ocurrido aiempre, y así ocurre hoy todavía más, por la intervención de los medios de comunicación. Si algo debe creer la Iglesia es que sólo la verdad puede vencer al error; no la fuerza. $\mathrm{Y}$ por tanto, debe hacer auyas las palabras de un historiador del modernismo, quien le recuerda que todo verdadero magisterio consiste realmente en ensenar, más que en amordezar simplemente:

El mentís dado a soluciones funestas trae por sí mismo la obligación de reemplazarlas por una más adecuada. Es decir: para combatir eficazmente al modernismo no hay otro remedio que resnudar en mejor sentido la tarea ante la cual él ha fracasado. 31

\section{A modo de propuesta}

Todas estas consideraciones gon obvias y no deberí hecer falta alargarlas más. El problema es concretarlas y haserlas operativas. Para no hacer aquí reivindica. ciones en provecho propio, me limitaré a decir que bastaría con que, en este punto, se aceptase como vinculante, y se p:18iera en práctice, todo lo que dijo el sínodo de 1971. Aun cuando, jurídicamente hablando (como ya hemos comentado), tales recomendaciones no tengan fuerza legal, tienen, sin embargo, una gran fuerza moral que, en n'i opinión, no puede quedar desoída alegremente sin causar un escándalo juatificado Citemos pues las palabras del sínodo, para concluir este capítulo.

La Iglesia reconoce a todos el derechı a una conveniente libertad de expresión y de pensamiento, lo cual supone también el derecho a que cada uno sea escuchado en espíritu de diálogo, que mantenga una legítima variedad dentro de la Iglesia. Los procedimientos judiciales deben conceder al imputado el derecho a saber quiénes son sus acusadores, así como el derecho a una convenien. te defensa (Ecclesia, 1971, p. 2299). 


\section{$X$. Un sínodo sobre la mujer en la Iglesia}

La primera vez que publiqué este decálogo, con la promesa de ampliarlo algún día, terminaba con una especie de sueño sobre la convoca toria de un Segundo Concilio de Jerusalén. ${ }^{32}$ Rebajando ahora las aspiraciones utópicas, y pensando en aquello que parece inmediatamente factible, y cuya factibilidad ha hecho de hilo conductor en todo este trabajo, se hace necesario decir una palabra, antes de termi. nar, sobre el tema de la mujer en la Iglesia. La propuesta concreta podría ser ésta: uno de los próximos sínodos de obispos debería tratar del problema de la mujer en la Iglesia. A él debería ser invitado por la naturaleza misma del tema (y aunque sea de manera jurídicamente extraordinaria), un buen número de mujeres, además del correspondiente número de obispos.

No deseo ahora concretar más, sino justificar mejor la medida. En la Iglesia ca. tólica, uno siente, por ser varón, la misma mala conciencia qué debe uno sentir en la civilización occidental por el hecho de ser blanco, cuando contempla, no sólo situaciones hodiernes (como la de Sudáfrica y algunas de Estados Unidos), sino el trato que a lo largo de la historia pasada hemos dado los blancos a los negros.

Esa mala conciencia se agudiza cuando se percibe de cerca lo novedosa (y lo provocativa desde el punto de vista social) que resultaba la conducta de Jesús para con la mujer. Conducta que llevó al Nuevo Testamento a acuñar aquella [rase decieiva de que "en Cristo Jesús ya no hay varón y mujer," como no hay señor y esclavo ni judío y griego. ¿Es posible que no lo haya en Cristo, y sí lo haya en su Iglesia? Además, ese principio tiene hoy más posibilidades sociológicas de realización de las que tenía en la época del Nuevo Testamento. $Y$ en este punto hay también una sensibilidad ética ambiental, que es legítima y justa (aun cuando a veces pueda expre. sarse desviadamente).

Y sin embargo, el principio neotestamentario parece hoy más olvidado que en la Iglesia primera: esto es honrado reconocerlo, aunque luego se pueda conceder también, tranquilamente, que una equiparación en dignidad no implica necesaria y mecánicamente una igualación de funciones. Como se puede conceder también que quiź́s el tema del sacerdocio de la mujer no está teológicamente tan maduro como para aceptarlo de un plumazo; porque no estén suficientemente claras y maduras ni la teología de lo femenino en la Iglesia, que quizés tenga mucho que ver con la pneumatología (la cual es precisamente una de las disciplinas teológicas más insuficientes y menos abordadas, a pesar de las demandas ambientales), ni la teología del ministerio (que ha de pasar a ser concebido no como poder sagrado, sino como servicio). Se pueden conceder tranquilamente estas y otras matizaciones. Pero, a pesar de todo, sigue en pie que el lugar de la mujer en la Iglesia y en la teología de hoy no parecen conformes con la voluntad de Dios que se reveló en Jesús. Y, por tanto, sigue en pie que la Iglesie podría hacer en este punto más de lo que hace.

Porque, además, hay que añadir que la Iglesia debe probablemente mucho más a la generosidad y a la entrega con que la están sirviendo hoy muchas mujeres, que al protagonismo de sus varones. $Y$, sin embargo, en muchos de los problemas e incomprensiones suscitados por la renovación de las órdenes religiosas, las mujeres han sido tratadas con notable menor consideración y con más parcialidad hacia los grupos minoritarios y desobedientes, que los varones. $\mathrm{Y}$ han sabido responder 
con discreción y con silencio, atentas sólo a poder seguir trabajando en servicio de los hombres, y confiando más en el valor de su verdad que en la fuerza de la publicidad. Sería triste que - precisamente por eso- Roma las tratara con más dureza. Porque en el evangelio se habla de la esclava del Señor, pero no de la esclava del monseñor.

La propuesta práctica que aquí se hace es una de tantas, y no pretende ser la única posible. El sínodo de 1971 antes citado hizo otra propuesta que valdría iguaj. mente y que cayó en el vacío:

Insistimos igualmente para que las mujeres tengan su propia parte de responsabilidad y de participación en la vida comunitaria de la sociedad y también de la Iglesia. Proponemos que este tema sea sometido a un profundo estudio con medios adecuados, como por ejemplo una comisión mixta de hombres y mujeres, de religiosos y seglares de diversas condiciones y competencia (Ecclesia, 1971, p. 2299).

Y el sínodo hacía estas recomendaciones precisamente para aplicar a la Iglesia el principio de que "cualquiera que pretenda hablar de justicia a los hombres, debe él mismo ser justo a los ojos de los demás. Por tanto conviene que nosotros mismos hagamos un examen sobre las maneras de actuar... y el estilo de vida que se dan dentro de la Iglesia." También el sínodo extraordinario de 1985 dijo algo semejante, aunque con ese lenguaje abstracto que resulta caraclerístico de este sínodo, y que parecería que pretende reconocer lo que no puede negarse, pero de manera suficientemente vaga como para que no se materialice nunca.

Sea, pues, cual sea la propuesta concreta, lo único claro es que la Iglesia toda, jerarquía y fieles, debe sentir mala conciencia en este punto, y debe abordarlo pron. la y generosamente, preguntándose qué le pide su Señor para ser de verdad -y también aquí- una señal o sacramento de la salvación de Cristo entre los hombres. Porque si no, la Iglesia, que perdió en el siglo XVIII a los intelectuales y en el XIX a los obreros, podría acabar perdiendo en el siglo $\mathrm{XX}$ a las mujeres....33

\section{Conclusión}

"¿Soy yo acaso la Iglesia católica?... Me basta con estar dentro de ella." 34 Es. tas palabras de Agustín reflejan y resumen el sentido de las páginas anteriores. Ellas no quieren tener olra fuerza que la de la razón y la verdad que hayan podido expresar. Con ellas no se pretende imponer nada ni dar lecciones a nadie. Pero sí quieren contribuir a mentalizar y a crear opiniones, porque esa es una tarea teológica legítima, y porque la misma congregación de la fe acaba de recordar en su instrucción sobre libertad y liberación que sólo la verdad hace libres; y está claro que esa verdad que libera no es la verdad que cada cual decimos al olro o cada grupo dice a los demás, sino la que cada persona y cada grupo acogen y aceptan para sí mismos, cuando se abren dóciles y obedientes a ella.

Por eso estas páginas no se dirigen inmediatamente a la jerarquía de la Iglesia, sino - propiamente hablando- a la comunidad de creyentes $y$, sobre todo, a quienes comparten no sólo la fe, sino esa tarea de dar a la fe una articulación inte- 
lectual, que llamamos teolagía $E_{8}$ en esa comunidad donde deben ser rechazadas o aceptadas o corregidas o mejoradas, hasta configurar una mentalidad creyente $y$ una demanda evangélica. $\mathrm{Y}$ es porque esa mentalidad ya existe en buena parte, por lo que son dadas a la luz: porque tengo la certeza de que no reflejan exclusivamente el sentir de una persona, sino que den voz a un sensus fidelium difundido entre muchas comunidades creyentes, que quizá no son de las más tibias en su le. Tempoco hace falta señalar, además, el valor ecuménico de todas estas propuestas, dado que inciden en lo que constituye la acusación última y más definitive de las iglesias separadas a la Iglesia católica: haber sustituido la categoría cristiana y neotestamentaria de koinonía, por la categoria romana del imperio o la potestas. Hace muy poco, el papa escribía a los obispos brasileños este magnífico párrafo:

Les pido por mi parte su oración por mí, para que el nombre de servus servorum Dei dado por San Gregorio Magno a la misión pontificia, sea en mí una verdad. ${ }^{\prime 35}$

Al leer estas palabras ¿quién no sintonizará profundamente con ellas, y unirá su plegaria a la de los obispos brasileños? Pero, a la vez, ¿quién no percibe que - si esa oración es escuchada - tendrá consecuencias muy palpables no sólo en el terreno de las actitudes personales, sino también en el de las estructuras eclesiales que son, en muy buena parte, obra de las personas?

Pues bien, solo he querido decir que eses consecuencias me parecen un mandamiento muy real y muy serio que el Señor hace a la Iglesia de hoy. Aunque quizás yo no he sabido pintarlas bien.

\section{NOTAS}

1. Cfr. "Vaticano II. ¿Comienzo o Fin," en Razón y Fe, abril, 1985. PGrrafo citado pp. 372-373.

2. En Iglesia: Carisma y Poder. Saniander, 1982.

3. Del Primato morale e civile degli italiani (1843!), obra que ha sido comparada repetidas veces con Is de Fichte Reden an die deutsche Nation.

4. DS 2976.

5. Cuando Talleyrand propuso a la asamblea constituyente la nacionalización de los bienes del clero, la Iglesia (que era entonces una de las grandea propietarias de Francia) protestó denodadamente. Pero, antos deapués, el cardenal Conoalvi declaraba públicamente que Talleyrand tenía el mérito "de haber curado a la Iglesia de Francia de su apego a la riqueza que amenazaba hacerla morir, cuando para vivir basta con un poco de pan y un vaeo de agua" (Citado por D. Rops, La Iglesia de las revoluciones, Barcelona, 1961, I, 206).

6. Citado por R.G. Villoslada. Historia de la Iglesia católice, BAC. 1953, II, 65.

7. Ese lue uno de los mayores méritos de la congregación De Propaganda Fide en aus origenes, cuando las misiones no conseguís distinguirse de las colonizaciones de los diversos imperios que las habian emprendido.

8. La Iglesia del renacimiento y la reforma, Barcelone, 1957, II, 328.

9. La Iglesia de los apóstoles y de los mórtires, Barcelona, 1955, 237.

10. Ep. XIII, 3 (PL 54,665). Cfr. Ep. XIV, 6 (PL 54,673): de cleri plebisque consensu debe informarse el metropolitano. San León da para ello razones de gran sentido común: "al que es conocido y aprobado se le reclama con paz, al desconocido es preciso imponerlo por la luerza"... "El que ha de presidir a todos sea elegido por todos" (qui praefururus est omnibus ab omnibus eligatur). Lo contrario será siempre "materia de disensión" (Ep. X, 6, PL 54,633.634).

11. "Carta a los fieles de León, Astorga y Mérida." En Obras, BAC, 1964, 634596. Subrayados míos. Anadamos también que el cisma donatiata arrancó precisamente de eata práclics. Y ello a la vez 
que no la recomienda como realizable tal cual o asambleariamente) es otro testimonio innegable de ella. Ochente obiapos declararon invalida la consagración epiecopal de Ceciliano, obiepo de Cartago, por sospechar que habla aido consagrado por un obiepo treditor, o apóstata. En su lugar pusieron a otro obiepo "puro," cuyo sucesor eerla Donato.

12. Citado por H. Jedin (Ed.). Manwal de historio de la Iglesia, Herder, 1977, VII, 567.

13. Entreasco agunos parralos: "En los primeros anos despute del Concilio - dice el Cardenal Ralzinger - parecla que el candidato al episcopado debía ser un sacerdote que ante todo estuviera abierto al mundo... No creo sinceramente que la Santa Sede oe dejara guiar durante esos atos por un criterio de apertura indiscriminado como parece indicar (el cardenal Hatzinger). El habla de ezperiencias amargas refiriendose a la conducta de algunos obiapos nombrados durante eas época. Hen existido... como han exiatido siempre en la largulaima historia de la Iglesia. Pero hay que reco. nocer honradamente que han sido excepciones; lamentables, muy lamentables si se quiere, pero eI. cepciones... En vez de permanecer a la defensiva, enceramados en nuestras posiciones y mirando con recelo a los avences de la humanidad, la Iglesia, como el amarilano del Evangelio (ln comparación es del mismo Pablo VI) debe acercaree al mundo para ayudarlo, pare sanarle ous heridas. La imposición, ademér, y el autoritarismo tienen actualmente mala acogida... Hacen falta obispos abiertos, dielogantes, comprensivoe, que sean a la vez firmes en la fe y aepan guardar el depóaito que les ha sido contiado... Sería peligroso que, para evitar esas experiencias amargas, be repitieran otras experiencias no menos amargas, que se hen producido a lo largo de la historia de la Igleain." (En Vida Nueva, 12 abril 1986. p. 707).

14. Cfr. El Ciervo, juljo-agosto 1985, p. 38. Subrayados mioa.

15. Hacía sólo 14 años que Nicolás II habrla reservado a los cerdenales la designación del papa. Vease lo que diremos en el epartedo $\mathrm{V}$.

16. Ignacio de Antioquía, Ad Romanos, prólogo (BAC, p. 474).

17. Esta Calsíficación debió hacerse hacia 1080 , según conjetura R. García Villoslada, Op. cit. (en nota 6), 147. Más en el sire deja las coses D. Rops, La Iglesia del Renacimiento y de la Reforma, Barcelona, 1957, II, 389, quien concrete que el número de los primeros cardenales obispos no pasaba de siete.

18. Epist. VIII, 30 (PL 77, 933).

19. Cfr. No. 73.

20. Razbn y Fe, abril 1985, p. 374.

21. Ver los documentos y las reflexiones oobre ellos que recojo en La libertad de palabra en la Iglesia y en la teología. Antología comentada, Santander, 1985, pp. 14a, 25s, 137a.

22. R. G. Villoslada, $O p$. cit. 63.

23. Ibid. id. (gubrayedos míos).

24. Historia de la teología eristiana, Barcelona, 1984, p. 559.

25. Citado en Vida Nueva, 22 de junio 1968, p. 18. Y el croniata comenta, "magnífica advertencia para todos los detectadores de herejías."

26. Sobre La Sapinière puede verse el capitulo que le dedico en Memoria de Jesús, Memoria del pueblo. Santander, 1984, pp. 155as.

27. Ejercicios, No. 22.

28. "¿No te de tristeza leer a eoos 6ádicos de la ortodoria que sólo parecen hallar una gratificación para sus vida cuando lanzan un enateme?" (La teología de cada dín, Salamanca ,1976, p. 184). Estas palabres las escribl hace más de una década, y no sospecheba enlonces hasta qué punto había de confirmarlas, deggraciadamente, lá experiencia posterior.

29. Cf. Obras (BAC) lomo I pp. 72-73.

30. Ibid. pp. 73-76. Una desfiguraciún parecida es la que, en mi opinión, se percibie en un largo eacrito anónimo presentado a Roma conlra G. Gutiérrez. Esa des「iguración, probablemente, debe ser casi inevitable a los a taques humanos. Por ello sólo puede ser compenaada por el dílogo y el debate en el seno de la comunidad cientifice (o de teblogos en el caso que nos ocupa): eata compensación necesaria, y puesta por la naturaleza misma de las cosas, ea lo que se rehuye en la práctica de la denuncia, mucho más cuando es anónima.

31. J. Riviere, Le modernisme dans l'Eglise, Peris, 1929, p. 550.

32. Clr. Art. cit. (en nota 1) 374375 .

33. Crr. Iglesia viva, No. 121 (enero 1986), p. 86.

34. Enarr. in psalmos 36, 19. BAC XIX, p. 647.

35. CC. Vida Nueva, 10 mayo de 1946, p. 944. 
Digitalizado por Biblioteca "P. Florentino Idoate, S.J." Universidad Centroamericana José Simeón Cañas 